\title{
Acúmulo de Matéria Seca e Macronutrientes por Plantas de Merremia aegyptia ${ }^{1}$
}

\author{
Accumulation of Dry Matter and Macronutrients in Merremia aegyptia Plants
}

MARTINS, T.A. ${ }^{2}$, CARVALHO, L.B. ${ }^{3}$, BIANCO, M.S. ${ }^{4}$ e BIANCO, S. ${ }^{5}$

\begin{abstract}
RESUMO - Um experimento em casa de vegetação foi conduzido entre janeiro e junho de 2008, na FCAV/UNESP, Brasil, objetivando estudar a produção de massa seca, a marcha de absorção e o acúmulo de macronutrientes por Merremia aegyptia, uma importante planta daninha em culturas anuais e perenes no Brasil. As plantas foram cultivadas em vasos de $7 \mathrm{~L} \mathrm{com}$ substrato de areia, que foram irrigados diariamente com solução nutritiva de Hoagland \& Arnon. Os tratamentos corresponderam às épocas de avaliação, em intervalos de 14 dias, iniciando-se 21 dias após a emergência (DAE). Em cada avaliação, as plantas de quatro vasos foram analisadas quanto à produção de massa seca e ao conteúdo de macronutrientes. M. aegyptia apresentou pequeno acúmulo de massa seca e de macronutrientes no início da fase experimental, os quais foram intensificados após $49 \mathrm{DAE}$. As folhas foram as principais estruturas acumuladoras de massa seca na primeira metade do ciclo de $M$. aegyptia, enquanto os caules o foram na segunda metade. $\mathrm{N}$ e K foram os macronutrientes mais acumulados em plantas de $M$. aegyptia. O período de máximo acúmulo teórico de massa seca e macronutrientes por M. aegyptia ocorreu entre 146 e 160 DAE.
\end{abstract}

Palavras-chave: plantas daninhas, Convolvulacea, jitirana, crescimento, nutrição.

ABSTRACT - A greenhouse experiment was carried out from January to June 2008 at FCAV/ UNESP, Brazil, to study dry mass production, absorption rate and macronutrient accumulation in Merremia aegyptia, an important weed in annual and perennial crops in Brazil. The plants were grown in seven liter pots with sand substrate and irrigated with Hoagland and Arnon nutrient solution. The treatments corresponded to the evaluation times, at 14 day intervals, beginning at 21 days after emergence (DAE). Plants of four pots were analyzed for growth and mineral nutrition. M. aegyptia showed small dry mass and macronutrient accumulation at the beginning of the experimental stage, which was intensified after 49 DAE. The main structures accumulating dry mass in the first half-stage were the leaves, and in the second half-stage, the stems. $N$ and $K$ accumulated more in $\boldsymbol{M}$. aegyptia plants. The maximum theoretical period of dry mass and macronutrients for M. aegyptia occurred between 146 and 160 DAE.

Keywords: weeds, Convolvulacea, hairy merremia, growth, nutrition.

\section{INTRODUÇÃO}

Merremia aegyptia, conhecida popularmente por jitirana ou corda-de-viola, é uma espécie vegetal de hábito trepador, pertencente à família Convolvulacea, que pode acarretar sérios problemas à colheita mecanizada em áreas de cultivo agrícola (Kissmann \& Groth, 1999). Atualmente, essa espécie tem-se destacado como planta daninha em áreas de

1 Recebido para publicação em 31.3.2010 e na forma revisada em 17.12.2010.

Parte do Trabalho de Graduação em Agronomia do primeiro autor.

2 Engo-Agr ${ }^{\circ}$., Centro de Pesquisa Fundação Mokiti Okada, Ipeúna-SP, ${ }^{3}$ Doutorando em Agronomia (Produção Vegetal), Faculdade de Ciências Agrárias e Veterinárias, Universidade Estadual Paulista "Júlio de Mesquita Filho" - FCAV/UNESP, Jaboticabal-SP, Bolsista CNPq, <agrolbcarvalho@gmail.com>; ${ }^{4}$ Mestrando em Agronomia (Produção Vegetal), FCAV/UNESP, Jaboticabal-SP, Bolsista CAPES; ${ }^{5}$ Professor Adjunto, Dep. de Biologia Aplicada à Agropecuária, FCAV/UNESP, Jaboticabal-SP. 
plantio direto, principalmente na cultura do milho, e em áreas de cana-crua, onde uma espessa camada de palha é mantida sobre o solo, pois a presença da palha não interfere na emergência de plantas da familia Convolvulacea, aumentando seu potencial de infestação em relação a outras plantas daninhas, o que está acarretando seleção de espécies dessa família nessas áreas (Correia \& Durigan, 2004; Kuva et al., 2007; Monquero et al., 2008).

Considerando a importância atual de $M$. aegyptia como planta daninha, há necessidade de estudos básicos a respeito da biologia dessa espécie, envolvendo aspectos relacionados a reprodução, crescimento, desenvolvimento, exigências em nutrientes, respostas aos sistemas de controle e outros, visando obter informações que possam auxiliar no seu manejo. Segundo Bianco et al. (2004a,b), esses estudos básicos são fundamentais para entender o comportamento das plantas daninhas sob diferentes condições ambientais e, também, para fornecer subsídios para predições de seu sucesso como infestante em função de novas práticas agrícolas e da introdução em novos ambientes.

Estudos a respeito de requerimentos nutricionais por plantas daninhas são de suma importância para a ciência das plantas daninhas, pelo fato de que, segundo Pitelli (1985), a competição por nutrientes é um dos principais fatores ecológicos que afetam negativamente a produtividade das culturas agricolas, assim como a competição por luz e água. Há trabalhos publicados a respeito de requerimentos nutricionais de plantas daninhas que destacam a importância desse tipo de estudo, podendo-se citar os de Rodrigues et al. (1995) com Commelina benghalensis, Erasmo et al. (2000) com Senna obtusifolia, Souza Filho et al. (2000) com Urena lobata, Gravena et al. (2002) com Hyptis suaveolens, Brighenti et al. (2003) com Cardiospermum halicacabum, Bianco et al. (2004a,b, 2005a,b, 2007, 2008, 2010) com Rottboelia exaltata, Desmodium tortuosum, Indigofera hirsuta, Brachiaria decumbens, Glycine max, Euphorbia heterophylla, Senna obtusifolia e Solanum americanum, respectivamente, além de Kazda et al. (2004) com Quercus petraea, Fagus sylvatica e Acer pseudoplatanus, Pedrinho Júnior et al. (2004) com Glycine max e Richardia brasiliensis,
Carvalho et al. (2007) com Zea mays e Brachiaria plantaginea, Duarte et al. (2008) com Ipomoea nil e Carvalho et al. (2009) com Ipomoea quamoclit.

O objetivo desta pesquisa foi estudar a produção de massa seca, a marcha de absorção e o acúmulo de macronutrientes por plantas de $M$. aegyptia cultivadas em condições padronizadas de nutrição mineral.

\section{MATERIAL E MÉTODOS}

O experimento foi conduzido em casa de vegetação do Departamento de Biologia Aplicada à Agropecuária, da Faculdade de Ciências Agrárias e Veterinárias - UNESP campus de Jaboticabal, SP, no período de janeiro a junho de 2008, utilizando vasos de plástico com capacidade para 7 litros, tendo como substrato para crescimento areia de rio lavada e peneirada.

A semeadura foi feita em meados de janeiro de 2008, utilizando sementes coletados em campo. Quando as mudas atingiram o estádio de dois pares de folhas verdadeiras totalmente expandidas, foi efetuado o desbaste, deixando-se apenas quatro plantas por vaso. Os vasos foram irrigados com solução nutritiva completa de Hoagland \& Arnon (1950), recebendo $25 \%$ da concentração original durante os primeiros 35 dias e, posteriormente, $50 \%$ até o final da fase experimental.

O delineamento experimental utilizado foi o inteiramente casualizado, com dez tratamentos e quatro repetições. Os tratamentos constituíram-se em épocas de avaliação, realizadas em intervalos de 14 dias, iniciandose aos 21 dias após a emergência (DAE), a saber: $21,35,49,63,77,91,105,119,133$ e 147 DAE. As repetições constituíram-se nos quatro vasos avaliados por época de avaliação.

Em cada época de avaliação, as plantas de quatro vasos foram coletadas e separadas em raizes, caules e folhas. A seguir, todo o material foi submetido à rápida imersão em solução diluída de detergente neutro, lavagem por imersão em água destilada e, finalmente, imersão em água deionizada (Sarruge \& Haag, 1974). Após esse procedimento de lavagem, as diferentes partes das plantas foram acondicionadas em sacos de papel devidamente 
identificados e perfurados, para posterior secagem em estufa de renovação forçada de ar a $60-70{ }^{\circ} \mathrm{C}$ por 96 horas.

A massa seca foi obtida pesando-se o material seco em balança eletrônica com precisão de centésimos de gramas. Após a pesagem, o material foi moído em micromoinho tipo Wiley, em malha de $20 \mathrm{~mm}$, e armazenado em frascos de vidros hermeticamente fechados.

Após a moagem do material seco, foram determinados os teores de macronutrientes. $\mathrm{O}$ nitrogênio total $\left(\mathrm{N}_{\text {total }}\right)$ e o fósforo $(\mathrm{P})$ foram determinados pelos métodos semimicro Kjedahl e colorimétrico do ácido fosfovanadatomolíbdico, respectivamente, conforme descrito por Sarruge \& Haag (1974). Na extração de potássio $(\mathrm{K})$, cálcio $(\mathrm{Ca})$ e magnésio $(\mathrm{Mg})$ foi utilizado o método descrito por Jorgensen (1977), por meio de espectrofotometria de absorção atômica. O S foi determinado pelo método turbidimétrico, descrito por Vitti (1989).

Os acúmulos de nutrientes para as partes da planta foram descritos multiplicando-se o teor do nutriente pela massa seca correspondente. $\mathrm{O}$ acúmulo total foi obtido por meio do somatório dos acúmulos das diferentes partes da planta, enquanto o teor total da planta foi obtido pela relação entre o acúmulo total da planta e a massa seca total correspondente.

Para cálculo do acúmulo total teórico de massa seca e macronutrientes, utilizou-se a equação exponencial $\mathrm{y}=\exp \left(\mathrm{a}+\mathrm{bx}+\mathrm{cx}^{2}\right)$, sendo y o acúmulo de massa seca e macronutriente e $\mathrm{x}$ os dias após a emergência. As curvas foram ajustadas utilizando-se o software Statistica 6.0 (Statsoft, 2006), em função dos dias do ciclo de vida da planta, refletindo um esboço comportamental da espécie em relação ao nutriente estudado.

Os pontos de máximo acúmulo teórico de massa seca e macronutrientes foram determinados pela derivada primeira e segunda da equação ajustada aos dados obtidos, utilizando o software Maple V (Char et al., 1991).

\section{RESULTADOS E DISCUSSÃO}

O acúmulo de massa seca por $M$. aegyptia foi lento no início do período experimental, atingindo o máximo valor teórico de 166,85 g por planta próximo aos $155 \mathrm{DAE}$ (Figura 1). Duarte et al. (2008) e Carvalho et al. (2009) observaram que plantas de $I$. nil e $I$. quamoclit apresentaram máximo acúmulo de $33,56 \mathrm{~g}$ por planta aos $123 \mathrm{DAE}$ e de 6,46 g por planta aos $146 \mathrm{DAE}$, respectivamente. Após $155 \mathrm{DAE}$, houve redução na massa seca acumulada de M. aegyptia. Essa redução ocorreu devido à senescência de folhas, como afirmaram Duarte et al. (2008) e Carvalho et al. (2009) após observarem comportamento semelhante em plantas de $I$. nil e $I$. quamoclit, respectivamente.

Foi verificado grande acúmulo de massa seca de 77 a 133 DAE (Figura 1), assim como observado por Carvalho et al. (2009) em I. quamoclit. Duarte et al. (2008) também observaram maior acúmulo de massa seca, iniciando-se após $77 \mathrm{DAE}$, em plantas de I. nil. Nesse período, esse grande aumento na massa seca de $M$. aegyptia ocorreu principalmente em função do acúmulo nos caules (Figura 2), sendo o mesmo observado em I. nil e I. quamoclit, o que pode ser explicado pelo fato de essas espécies apresentarem hábito de crescimento trepador com longos caules (Lorenzi, 2000). Além disso, o ciclo de vida dessas espécies é mais prolongado que o de culturas anuais, acarretando problemas na colheita e perdas indiretas quando não controladas (Carvalho et al., 2009).

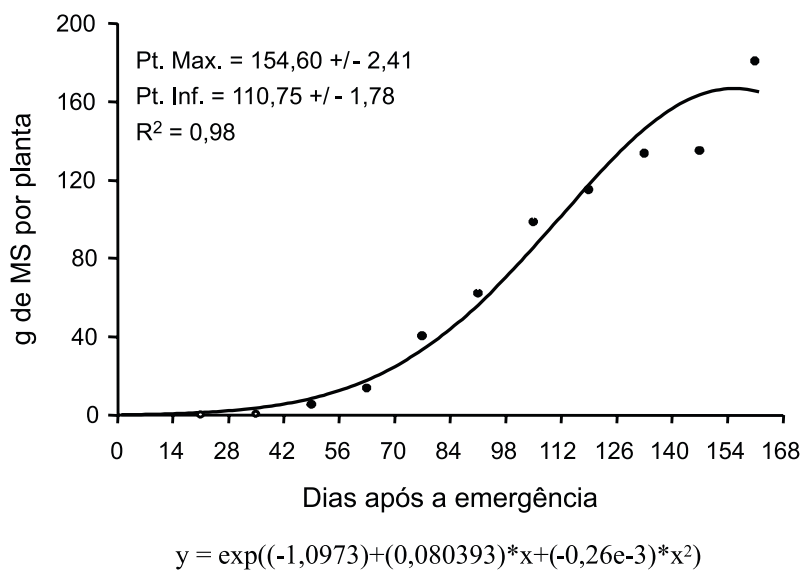

Figura 1 - Acúmulo de massa seca por Merremia aegyptia no decorrer do período experimental, equação ajustada, respectivos pontos de máximo e inflexão e +/- desvio-padrão da média das quatro repetições. 


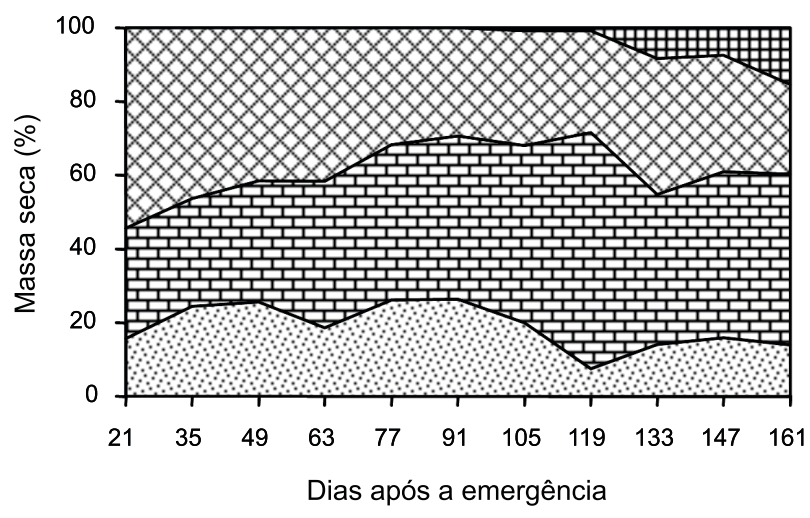

Raízes 回Caules 区folhas 田P. Reprodutiva

Figura 2 - Distribuição percentual da massa seca nas diferentes partes da planta de Merremia aegyptia no decorrer do período experimental.

Dividindo o período experimental em três partes, a porcentagem de acúmulo de massa seca em folhas foi maior que nas outras estruturas na primeira parte, enquanto a porcentagem em caules foi maior na terceira parte do período experimental (Figura 2). Esse fato também foi verificado por Duarte et al. (2008) e Carvalho et al. (2009), sendo esse comportamento atribuído ao hábito de crescimento das espécies.

A porcentagem de acúmulo de massa seca nos caules aumentou após 49 DAE em detrimento principalmente das folhas de M. aegyptia (Figura 2). Isso permitiu maior porcentagem de acúmulo de massa seca nos caules do que nas outras estruturas da planta de 91 a 147 DAE. Segundo Carvalho et al. (2009), isso pode ser explicado pelo hábito de crescimento das espécies, as quais têm caules que crescem rapidamente, permitindo à planta buscar luz necessária à fotossíntese.

O florescimento de $M$. aegyptia ocorreu entre 91 e 105 DAE; a porcentagem de massa seca acumulada nas estruturas reprodutivas foi pequena, se comparada à da planta inteira, atingindo o maior valor (15,40\%) aos $161 \mathrm{DAE}$ (Figura 2). Duarte et al. (2008) e Carvalho et al. (2009) também verificaram pequenas quantidades de massa seca acumulada nessas estruturas em plantas de I. nil e I. quamoclit; além disso, esses autores observaram que os maiores valores ocorreram no final do período experimental.
A sequência de macronutrientes com mais altos teores em plantas de $M$. aegyptia foi $\mathrm{K}>$ $\mathrm{N}>\mathrm{Ca}>\mathrm{MG}>\mathrm{S}>\mathrm{P}$, com valores variando no decorrer do periodo experimental (Tabela 1). Aos $49 \mathrm{DAE}$, foram observados os maiores teores de N, P e K, enquanto os maiores teores de $\mathrm{Ca}$ e $\mathrm{Mg}$ foram verificados aos $63 \mathrm{DAE}$. Contudo, o maior teor de $\mathrm{S}$ foi observado aos 91 DAE. Estudando nutrição mineral de plantas daninhas de folhas largas, Bianco et al. (2004b, 2005a, 2007, 2008, 2010) e Pedrinho Júnior et al. (2004) observaram que N e K foram os macronutrientes encontrados em maiores quantidades em plantas de $D$. tortuosum, R. brasiliensis, I. hirsuta, E. heterophylla, S. americanum e $S$. obtusifolia, respectivamente. Duarte et al. (2008) e Carvalho et al. (2009) também relataram maiores teores de $\mathrm{N}$ e $\mathrm{K}$ em plantas de $I$. nil e $I$. quamoclit, respectivamente. Esse fato evidencia que $\mathrm{N}$ e $\mathrm{K}$ são os macronutrientes mais exigidos por essas plantas daninhas já estudadas.

$\mathrm{O}$ acúmulo de macronutrientes em plantas de $M$. aegyptia foi pequeno no início, aumentando após a primeira parte do período experimental (Figura 3). Um grande acúmulo de $\mathrm{N}, \mathrm{K}$ e $\mathrm{Mg}$ foi verificado de 49 a $133 \mathrm{DAE}$; para $\mathrm{P}$ e Ca isso ocorreu de 63 a $133 \mathrm{DAE}$, e para $\mathrm{S}$, de 63 a 119 DAE. A planta de $M$. aegyptia acumulou o máximo valor teórico de $2.887,78 \mathrm{mg}$ de $\mathrm{N}$ por planta aos $160 \mathrm{DAE}$, $287,54 \mathrm{mg}$ de $\mathrm{P}$ por planta aos $146 \mathrm{DAE}$, $2.896,59 \mathrm{mg}$ de $\mathrm{K}$ por planta aos $160 \mathrm{DAE}$, $2.579,21 \mathrm{mg}$ de Ca por planta aos $150 \mathrm{DAE}$, $553,62 \mathrm{mg}$ de $\mathrm{Mg}$ por planta aos $148 \mathrm{DAE}$ e 224,62 mg de S por planta aos 146 DAE.

Tabela 1 - Teor de macronutrientes na planta de Merremia aegyptia no decorrer do período experimental

\begin{tabular}{|c|c|c|c|c|c|c|}
\hline \multirow{2}{*}{ DAE $^{1 /}$} & $\mathrm{N}$ & $\mathrm{P}$ & $\mathrm{K}$ & $\mathrm{Ca}$ & $\mathrm{Mg}$ & $\mathrm{S}$ \\
\cline { 2 - 7 } & \multicolumn{6}{|c|}{$\left(\mathrm{g} \mathrm{kg}^{-1}\right.$ de massa seca $)$} \\
\hline 21 & 31,13 & 1,45 & 35,45 & 13,27 & 3,47 & 1,33 \\
\hline 35 & 26,30 & 1,20 & 31,37 & 11,89 & 3,35 & 1,26 \\
\hline 49 & 35,25 & 2,63 & 56,11 & 18,21 & 5,52 & 1,73 \\
\hline 63 & 31,56 & 2,39 & 39,53 & 21,91 & 6,23 & 1,60 \\
\hline 77 & 23,31 & 2,54 & 29,34 & 19,53 & 5,47 & 1,61 \\
\hline 91 & 22,65 & 2,24 & 23,59 & 14,34 & 4,39 & 1,96 \\
\hline 105 & 18,40 & 1,98 & 16,85 & 16,07 & 3,63 & 1,85 \\
\hline 119 & 18,83 & 1,54 & 15,13 & 20,69 & 3,41 & 1,67 \\
\hline 133 & 18,29 & 1,66 & 15,69 & 15,99 & 2,67 & 1,40 \\
\hline 147 & 18,65 & 2,27 & 19,09 & 14,38 & 2,89 & 1,66 \\
\hline 161 & 16,28 & 1,37 & 14,29 & 15,65 & 3,14 & 1,67 \\
\hline
\end{tabular}

1/ DAE $=$ dias após a emergência. 

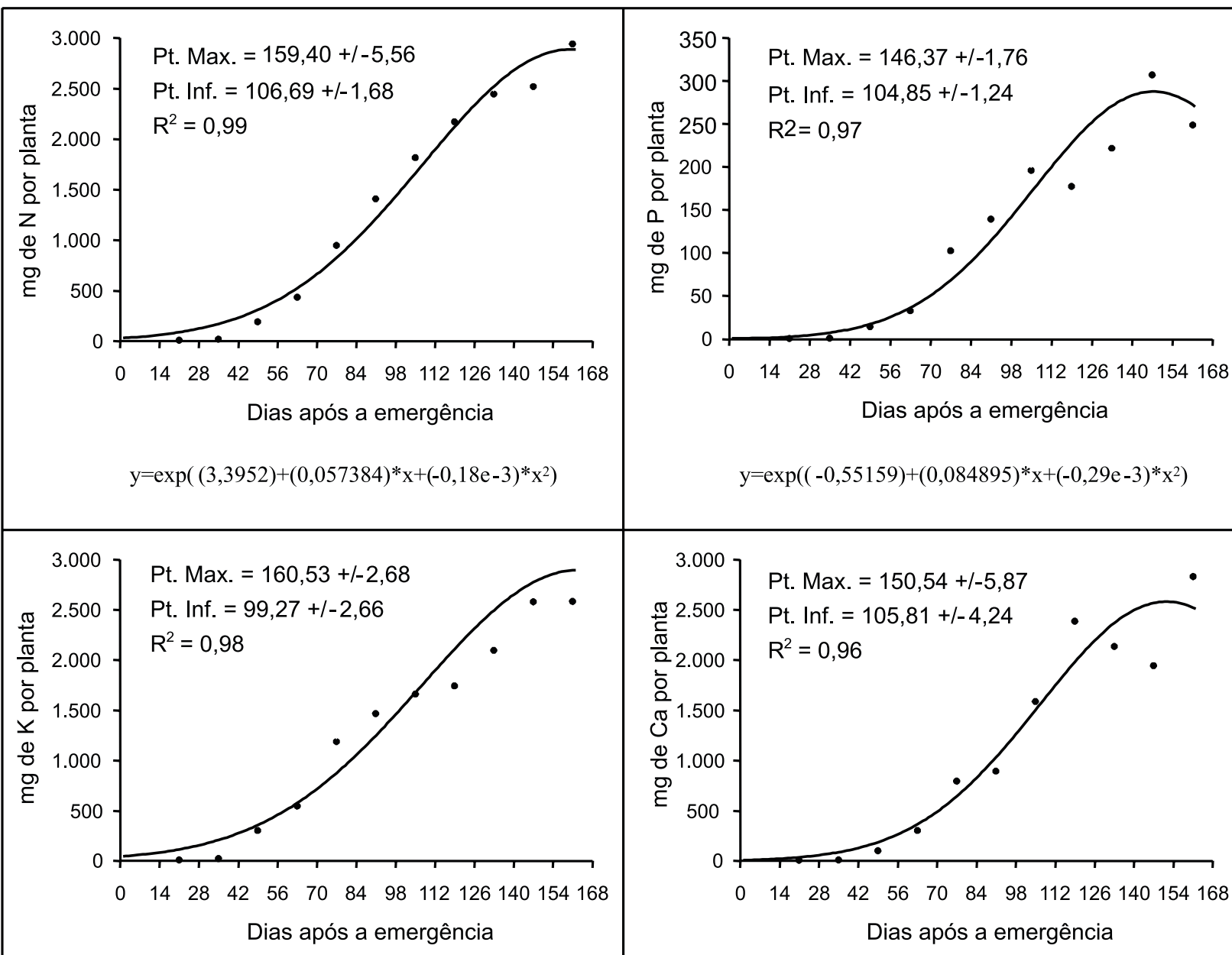

$y=\exp \left((-0,55159)+(0,084895) * x+(-0,29 e-3) * x^{2}\right)$

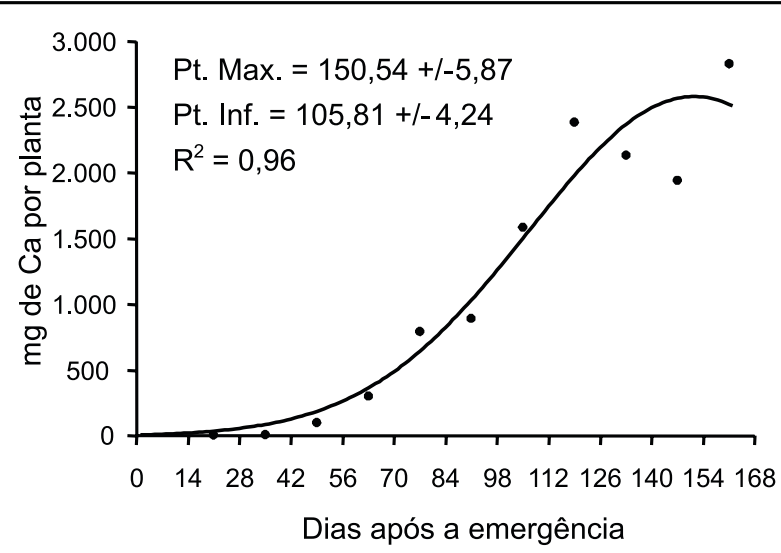

$y=\exp \left((3,74488)+(0,052011) * x+(-0,16 e-3) * x^{2}\right)$

$y=\exp \left((2,19004)+(0,075268) * x+(-0,25 e-3) * x^{2}\right)$
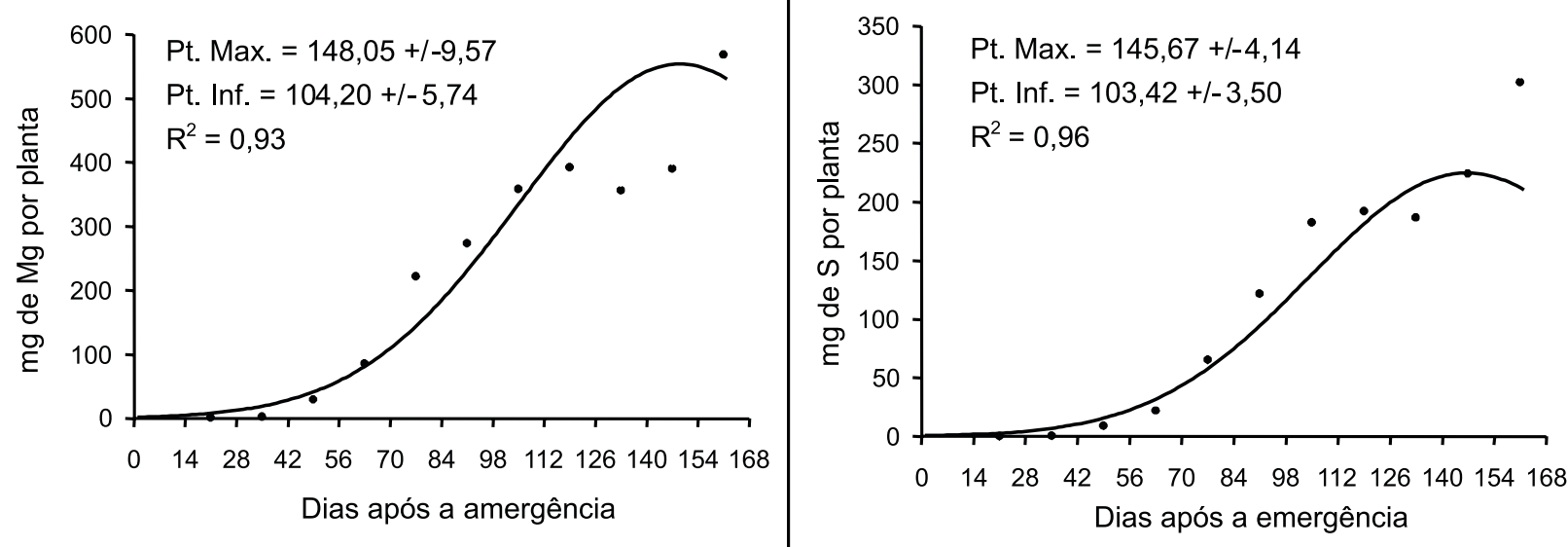

$\mathrm{y}=\exp \left((0,61783)+(0,076986) * \mathrm{x}+(-0,26 \mathrm{e}-3) * \mathrm{x}^{2}\right)$

$y=\exp \left((-0,52742)+(0,081578) * x+(-0,28 e-3) * x^{2}\right)$

Figura 3 - Curvas de acúmulos totais de nitrogênio $(\mathrm{N})$, fósforo $(\mathrm{P})$, potássio $(\mathrm{K})$, cálcio $(\mathrm{Ca})$, magnésio $(\mathrm{Mg})$ e enxofre $(\mathrm{S})$ por Merremia aegyptia no decorrer do período experimental, equação ajustada, respectivos pontos de máximo e inflexão e +/desvio-padrão da média das quatro repetições. 
Comparando as três espécies da família Convolvulacea já estudadas, no ponto de máximo acúmulo teórico, $M$. aegyptia acumulou substancialmente mais macronutrientes que $I$. nil $(791,79 ; 50,82 ; 780,63 ; 362,96$; 139,68; e 38,71 g por planta de N, P, K, Ca, Mg e S, respectivamente) e I. quamoclit $(167,62$; 15,$41 ; 149,46 ; 74,48 ; 26,88$; e 14,80 g por planta de N, P, K, Ca, Mg e S, respectivamente). Assim, pode-se evidenciar que $M$. aegyptia é muito mais exigente em macronutrientes que essas duas outras espécies, ou seja, apresenta maior habilidade competitiva e, por isso, pode interferir mais intensamente no desenvolvimento das culturas agrícolas.

Os macronutrientes mais acumulados em plantas de $M$. aegyptiaa foram aqueles que apresentaram maiores teores. A sequência de acúmulo foi $\mathrm{K}>\mathrm{N}>\mathrm{Ca}>\mathrm{Mg}>\mathrm{P}>\mathrm{S}$. Bianco et al. (2004a, b, 2007, 2010) e Pedrinho Júnior (2004), estudando plantas daninhas de folhas largas, e Duarte et al. (2008) e Carvalho et al. (2009), estudando espécies da família Convolvulacea, verificaram que $\mathrm{N}$ e $\mathrm{K}$ foram os macronutrientes mais acumulados nessas espécies. N e K também são os macronutrientes mais exigidos pela maioria das culturas agrícolas de interesse econômico (Epstein \& Bloom, 2005). A maior exigência desses dois nutrientes deve-se a suas funções na planta. $\mathrm{N}$ tem função estrutural, constituinte de aminoácidos, proteínas, clorofila, hormônios vegetais etc., enquanto $\mathrm{K}$ é ativador de mais de 40 enzimas e principal cátion responsável pela manutenção do turgor e da eletroneutralidade celular (Taiz \& Zeiger, 2006).

De acordo com o relatado, pode-se inferir, portanto, que a competição por macronutrientes exercida por plantas de $M$. aegyptia pode ser um importante fator biótico que afeta negativamente o crescimento, o desenvolvimento e a produção das culturas.

Bianco et al. (2004a,b, 2007) relataram que o período de maior competição entre plantas daninhas e culturas anuais no Brasil fica em torno de $77 \mathrm{DAE}$, em consequência da intensificação na assimilação de nutrientes pelas plantas (Carvalho et al., 2009), também observada nesta pesquisa. Durante esse período, uma planta de $M$. aegyptia acumulou 40,47 g de massa seca; 943,87 mg de N; 102,78 g de P; $1.187,12$ g de K; 790,58 g de Ca; 221,22 g de
Mg; e 65,30 g de S. Comparando esses resultados com os obtidos para I. nil e I. quamoclit, pode afirmar-se que $M$. aegyptia é muito mais competitiva por macronutrientes que as demais espécies da família Convolvulacea já estudadas, aos $77 \mathrm{DAE}$, crescendo sob as mesmas condições nutricionais.

Ainda, é importante evidenciar que, considerando a média dos valores dos pontos de inflexão e de máximo acúmulo teórico, a taxa de acúmulo diário de massa seca e de macronutrientes em $M$. aegyptia foi crescente até $105 \mathrm{DAE}$, e o maior acúmulo de massa seca e de macronutrientes ocorreu aos 152 DAE. Esses dados permitem inferir que a competição mais intensa por macronutrientes pode ocorrer apenas em um estádio de desenvolvimento da cultura muito avançado. Contudo, a exigência nutricional de $M$. aegyptia, aos $77 \mathrm{DAE}$, é muito alta se comparada à das espécies de plantas daninhas já estudadas e também à de muitas culturas agrícolas citadas por Epstein \& Bloom (2005). Assim, a competição por nutrientes exercida por $M$. aegyptia seria uma fator limitante ao crescimento das culturas agrícolas, além da interferência indireta na colheita, que ocorre em função do hábito trepador da planta daninha.

Conclui-se que: as folhas são as principais estruturas acumuladoras de massa seca na primeira metade do ciclo de $M$. aegyptia, enquanto os caules o são na segunda metade; $N$ e K são os macronutrientes mais acumulados em plantas de $M$. aegyptia; e o período de máximo acúmulo teórico de massa seca e macronutrientes por $M$. aegyptia ocorre entre 146 e 160 DAE.

\section{LITERATURA CITADA}

BIANCO, S.; BARBOSA JÚNIOR, A. F.; PITELLI, R. A. Crescimento e nutrição mineral de capim-camalote. Planta Daninha, v. 22, n. 3, p. 375-380, 2004a.

BIANCO, S.; BARBOSA JÚNIOR, A. F.; PITELLI, R. A. Crescimento e acúmulo de macronutrientes em Indigofera hirsuta. Ensaios Ci., v. 9, n. 4, p. 431-438, 2005 a.

BIANCO, S.; CARVALHO, L. B.; BIANCO, M. S. Growth and mineral nutrition of Solanum americanum. Planta Daninha, v. 28, n. 2, p. 293-399, 2010 
BIANCO, S.; PITELLI, R. A.; BELLINGIERI, P. A. Crescimento e nutrição mineral de Desmodium tortuosum (Sw.) DC. Cult. Agron., v. 13, n. 1, p. 78-88, $2004 b$.

BIANCO, S.; PITELLI, R. A.; CARVALHO, L. B. Estudo comparativo do acúmulo de massa seca e macronutrientes por plantas de Glycine max (L.) Merr. e Euphorbia heterophylla

L. Ensaios Ci., v. 11, n. 1, p. 61-72, 2007.

BIANCO, S.; PITELLI, R. A.; CARVALHO, L. B. Crescimento e nutrição mineral de fedegoso. Ci. Cult., v. 3, p. $35-41,2008$

BIANCO, S.; TONHÃ̃, M. A. R.; PITELLI, R. A. Crescimento e nutrição mineral de capim-braquiária. Planta Daninha, v. 23, n. 3, p. 423-428, 2005 b.

BRIGHENTI, A. M.; VOLL, E.; GAZZIERO, D. L. P. Biologia e manejo do Cardiospermum halicacabum.

Planta Daninha, v. 21, n. 2, p. 229-237, 2003

CARVALHO, L. B. et al. Estudo comparativo do acúmulo de massa seca e macronutrientes por plantas de milho var. BR-106 e Brachiaria plantaginea. Planta Daninha, v. 25, n. 2, p. 293-301, 2007.

CARVALHO, L. B.; BIANCO, S.; PITELLI, R. A. Growth and mineral nutrition of Ipomoea quamoclit.

Planta Daninha, v. 27, n. 2, p. 283-288, 2009.

CHAR, B. W. et al. Maple V: language reference manual. New York: Springer-Verlag, 1991. 411 p.

CORREIA, N. M.; DURIGAN, J. C. Emergência de plantas daninhas em solo coberto com palha de cana-de-açúcar. Planta Daninha, v. 22, n. 1, p. 11-17, 2004.

DUARTE, D. J. et al. Crescimento e nutrição mineral de Ipomoea nil. Planta Daninha, v. 26, n. 3, p. 577-583, 2008.

EPSTEIN, E.; BLOOM, A. J. Mineral nutrition of plants: principles and perspectives. 2.ed. Massachussets: Sinauer, 2005. $380 \mathrm{p}$.

ERASMO, E. A. L. et al. Efeito de níveis crescentes de calagem no crescimento e estado nutricional de fedegoso. Planta Daninha, v. 18, n. 2, p. 253-263, 2000.

GRAVENA, R. et al. Análise do crescimento de Hyptis suaveolens. Planta Daninha, v. 20, n. 2, p. 189-196, 2002.

HOAGLAND, D. R.; ARNON, D. J. The water culture method of growing plants without soil. Berkeley: University of California, 1950. 31 p. (Circular, 347).
JORGENSEN, S. S. Metodologia utilizada para análises químicas de rotina: guia analítico. Piracicaba: CENA, 1977. $24 \mathrm{p}$.

KAZDA, M. et al. Importance of mineral nutrition for photosynthesis and growth of Quercus petraea, Fagus sylvatica and Acer pseudoplatanus planted under Norway spruce canopy. Plant Soil, v. 264, n. 1, p. 25-34, 2004.

KISSMANN, K. G.; GROTH, D. Plantas infestantes e nocivas. 2.ed. São Paulo: BASF, 1999. Tomo II. 978 p.

KUVA, M. A. et al. Fitossociologia de comunidades de plantas daninhas em agroecossistema cana-crua. Planta Daninha, v. 25, n. 3, p. 501-511, 2007.

LORENZI, H. Plantas daninhas do Brasil: terrestres, aquáticas, parasitas e tóxicas. 3.ed. Nova Odessa: Instituto Plantarum, 2000. $608 \mathrm{p}$

MONQUERO, P. A. et al. Mapas de infestação de plantas daninhas em diferentes sistemas de colheita da cana-de-açúcar. Planta Daninha, v. 26, n. 1, p. 47-55, 2008.

PEDRINHO JÚNIOR, A. A. F.; BIANCO, S.; PITELLI, R. A. Acúmulo de massa seca e macronutrientes por plantas de Glycine max e Richardia brasiliensis. Planta Daninha, v. 22, n. 1, p. 53-61, 2004.

PITELLI, R. A. Interferências de plantas daninhas em culturas agrícolas. Inf. Agropec., v. 11, n. 1, p. 16-27, 1985.

RODRIGUES, B. N.; PITELLI, R. A.; BELLINGIERI, P. A Efeitos da calagem do solo no crescimento inicial e absorção de macronutrientes por plantas de trapoeraba (Commelina benghalensis). Planta Daninha, v. 13, n. 1, p. 59-68, 1995.

SARRUGE, J. R.; HAAG, H. P. Análises químicas em plantas. Piracicaba: Escola Superior de Agricultura Luiz de Queiroz, 1974. 56 p.

SOUZA FILHO, A. P. S.; VELOSO, C. A. C.; GAMA, J. R N. Capacidade de absorção de nutrientes do capim-marandu (Brachiaria brizantha) e da planta daninha malva (Urena lobata) em função do pH. Planta Daninha, v. 18, n. 3, p. $443-450,2000$.

STATSOFT, INC. Data analysis software system. Version 6.0. Disponível em: $<\mathrm{http}: / / \mathrm{www}$.statsoft.com>. Acesso em: 10 jan. 2010.

TAIZ, L.; ZEIGER, E. Plant physiology. 4.ed. Sunderland: Sinauer, 2006. 792 p.

VITTI, G. C. Avaliação e interpretação do enxofre no solo e na planta. Jaboticabal: FUNEP, 1989. 37 p. 